ARTICLE

\title{
Science by, with and for citizens: rethinking 'citizen science' after the 2011 Fukushima disaster
}

Joke Kenens ${ }^{1 凶}$, Michiel Van Oudheusden (1D ${ }^{2 凶}$, Go Yoshizawa (1) ${ }^{3 凶}$ \& Ine Van Hoyweghen (1) ${ }^{4 凶}$

\begin{abstract}
This study illustrates how citizen-driven radiation monitoring has emerged in post-Fukushima Japan, where citizens generate their own radiation data and measurement devices to provide public with actionable data about their environments. Drawing on ethnographic fieldwork in and around Fukushima Prefecture, it highlights the multifaceted character of these bottom-up, citizen-led efforts, contrasting these initiatives with the emergence of "citizen participatory" science policy discourses in Japan. Recognizing the contested nature of citizenship in Japan and in the nuclear arena, the article considers how terms and definitions shape the participation of citizens and other stakeholders (local communities, public authorities, regulators, and professional scientists) in science and technology in culturally and historically specific ways. It builds on these observations to open up new spaces of expertise, which engage all stakeholders through social-scientific intervention.
\end{abstract}

\footnotetext{
${ }^{1} \mathrm{KU}$ Leuven, SCK CEN, Leuven, Belgium. ${ }^{2}$ University of Cambridge, Cambridge, UK. ${ }^{3}$ Oslo Metropolitan University, Oslo, Norway. ${ }^{4}$ KU Leuven,

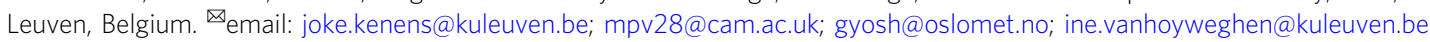




\section{Introduction}

- he 3/11 "triple disaster"-earthquake, tsunami, nuclear meltdown - has had a profound impact on Japanese society (Hindmarch, 2013). Not only has it caused severe human distress and material devastation, it has also eroded civic trust in Japan's energy policy, eliciting heavy criticism on the country's reliance on nuclear power and its approach to nuclear safety (ibid, Morita et al. 2013). The National Diet of Japan Fukushima Nuclear Accident Independent Investigation Commission (NAIIC) blamed the Japanese government for its slow and unresponsive management of the crisis, and called for more openness and transparency in the regulation of nuclear power and technology (NAIIC, 2012). Within days after the nuclear disaster, individuals and small groups of citizens began measuring radiation levels, borrowing or purchasing measurement devices to generate their own data on ionizing radiation contamination. These efforts emerged in response to an urgent public need for more reliable and actionable data, as governmental agencies, nuclear power plant operators, and emergency services failed to make such data available to the public in the wake of the catastrophe, and were even seen to deliberately spread biased information to sustain an illusion of safety (Morita et al. 2013). Observers point to the irony of these developments: whereas the Fukushima disaster devastated Japan and upset Japan's relatively stable patterns of state-and-civil-society relations, it has also reinvigorated civil society and citizen initiatives, leading citizens not only to challenge nuclear power, institutional science, and government, but also to organize themselves in unprecedented ways (Aldrich, 2013, Hasegawa, 2014).

To shed light on these citizen science initiatives, we build on a literature review of policy documents and guidelines published by the Japanese government, and on workshops with citizen scientists, which we hosted in Japan and Europe between 2017 and 2019. We also draw on multi-sited ethnographic fieldwork (Marcus, 1995) and interviews, conducted by the first author in Japanese, who visited 14 citizen radiation measuring organizations and 2 citizen science organizations in 2018, covering multiple geographical sites (Fukushima, Tochigi, Miyagi, Aichi, Tokyo, Kyoto) and organizations initiated in different timespans, dating back to the 1970s, the 1986 Chernobyl accident, and the Fukushima disaster. ${ }^{1}$

We explore these initiatives under the general rubric of "citizen science" - not with the aim of "subsuming" the sheer variety of citizen practices under one, presently trendy, "catchall" phrase (Strasser et al. 2018)-but precisely to open up issues of expertise, citizenship, and the role of (nuclear) science in society, which dominant Western and institutionally sanctioned notions of citizen science risk concealing (Eitzel et al. 2017). In Japan, these issues pertain to the development of social movements since the 1960 s and political activism, of which citizen engagement is an integral part (Yoshizawa, 2012). While taking into account the disastrous events leading up to the upsurge of citizen radiation measuring organizations, recognizing the case of Fukushima as a manifestation of "emancipatory catastrophism" (Beck, 1992), we also place these groups alongside expressions of citizen activism in postwar Japan. Therefore, we view citizen movements as an expression of an increased autonomy of the citizen vis-à-vis established institutions "as a way of dealing with modernity rather than as a barometer of democratization" (Avenell, 2006). Although the term "citizen science" is less common-and certainly less fashionable-among grassroots initiatives in Japan than in Europe and the United States, Japanese citizen radiation measuring organizations tap into a longer tradition of shimin kagaku (a Japanese term for citizen science) and the rise of antinuclear movements since the 1970s (Hasegawa, 2014).
With these observations in mind, the aim of this study is to highlight how terms and definitions shape the participation of citizens and other stakeholders (local communities, public authorities, regulators, and professional scientists) in science and technology in culturally and historically specific ways. To this end, we first contextualize citizen science within a Japanese historical, societal, and global context. Second, we draw attention to how the concept of citizen science materializes through top-down projects, government-sanctioned imperatives, as well as emerges from the bottom up in the field of radiological protection, i.e., in the hands of citizens and their collectives (Gabrys et al. 2016). We show how these diversified realizations simultaneously enrich and problematize a generic understanding of citizen science in Japan and in academic and policy discourses more broadly. Third, we discuss how opening up the definition of citizen science can create new spaces of expertise to the benefit of various stakeholders: local communities, public authorities, regulators, and professional scientists (including social scientists). These points are illustrated through several manifestations of citizen engagement emerged after the Fukushima nuclear accident in Japan, many of which are not well known and have not been systematically researched or theorized. By shedding light on these citizen participatory practices we respond to an ongoing debate regarding the distinctiveness of East Asian Science and Technology Studies (Lin and Law, 2018, Tsukahara, 2019); a discussion that directly concerns citizen science, given its close proximity to public participation in science and its historic relation to Science and Technology Studies (STS; see, e.g., Irwin, 1995). By highlighting how "citizen science" takes on specific forms in postFukushima Japan, while accommodating top-down policy dictates heard across the globe (e.g., the language of "co-creative innovation"), this study also puts flesh on the notion that there are "many modes of citizen science," many of which are now emerging and developing (Strasser et al. 2018).

\section{Pioneering Japanese citizen science}

A clear definition of citizen science seems difficult in any language and context, as various typologies of citizen science illustrate numerous interpretations of the concept, each highlighting different aspects of citizen science, such as the degree of citizen participation, and the relationships between citizens and scientists, among others (Bonney et al. 2009, Wiggins and Crowston, 2011, Shirk et al. 2012, Haklay, 2013, Perello et al. 2020). In addition to these considerations, Eitzel et al. (2017) demonstrate that the concept of citizen science acquires different connotations depending on the cultural and social context. This study builds on this point by considering the Japanese concepts of citizen science, namely shimin kagaku (市民科学) and shichizun saiensu (シチ ズンサイエンス), in their historical, contemporary, social, and cultural context. Although the first concept, shimin kagaku, for citizen science was introduced in the 1990s by the nuclear chemist and antinuclear activist Takagi (1999a, 1999b), the latter is a relatively new term, which is taken directly from the English word "citizen science".

As documented elsewhere (Avenell, 2016, Van Oudheusden et al. 2020), the nuclear chemist Takagi revisited the close intertwining between the state and science and technology in postwar Japan. He felt science and technology needed to "adopt the viewpoint of the citizen, the so-called 'science of citizens' (shimin kagaku)" (Takagi, 1999b, p.7, first author's translation) to constitute a legitimate alternative for vested institutions. This eventually led him to abandon industry and academics all together and to take up the challenge of becoming a citizen scientist himself. His reflections on science and technology mirror 
international movements among scholars and civil society in the 1960 s and 70s, as he drew inspiration from other concerned scientists such as Frank von Hippel in the United States and the rise of "science shops" in the Netherlands (Takagi, 1999a). In Japan, similar tendencies were forming as democratization and a growing awareness of the environmental and health costs of industrialization sometimes caused universities and researchers to align with residents (Fujigaki, 2015). ${ }^{2}$ On several occasions, including the Minamata disease and the Itai-Itai disease, this resulted in a rapprochement between scientists and citizens (Kaji, 2012, Fujigaki, 2015).

Parallel to these interpretations of citizen science in Japan, another form of shimin kagaku is expressed in Japan, which focuses on "a dynamism of autonomy (shutaisei) in which citizens become conscious of the problem themselves, collect and study necessary knowledge and conduct research" (Ueda, 2006, p.70, first author's translation). Representative of this strand is Ui Jun, a chemist and research assistant at the University of Tokyo, who organized open lectures (jishu kōza) at university to educate and empower citizens. Both interpretations of shimin kagaku still permeate contemporary understanding of citizen science in Japan, as the definition of the Citizen Science Initiative Japan, a non-governmental organization concerned with promoting citizen science in Japan demonstrates: "science of citizens, by citizens and for citizens" (Citizen Science Initiative Japan 2018, first author's translation). The memory of Takagi is also kept alive through the Takagi Fund, which provides support for citizen science initiatives, including citizen groups measuring radiation.

Despite the relative visibility of shimin kagaku in Japanese society through the work of among others Takagi and Ui, the term "citizen science" only entered Japanese governmental policy documents in the twenty-first century under the auspices of a "co-creative" Science Technology and Innovation policy. This policy seeks to "reinforce a platform for innovation of technology and science" and herald a move towards "open science" (Cabinet Office, 2015, first author's translation). In the Fifth Science and Technology Master Plan (Cabinet Office, 2015) citizen science, referred to as "shichizun saiensu" (シチズンサイエンス), ${ }^{3}$ is introduced as a "form of citizen participatory science" (shimin sankaku gata no saiensu) (ibid), eliciting a top-down understanding of participation in which citizens contribute data or local knowledge to science. Remarkably, the Japanese government opted to use a loanword, shichizun saiensu, taken from the English "citizen science", thereby indirectly inscribing Japanese citizen science into a Western conception and tendency towards increased citizen participation in research (Felt, 2018). The Ministry of Education, Culture, Sports Science and Technology (MEXT) was quick to adopt the aspirations of the Cabinet Office concerning the potential of citizen science into its 2015 White Paper:

"When it comes to the creation of innovation that changes society, 'citizen science' (shimin kagaku), which embraces ideas from daily life, is important, because the possibility that innovation is created, increases as new venues where experts and citizens collaborate, are developed. Moreover, the knowledge, skills and desires that citizens possess, sometimes surpass that of the expert. If we can bring this knowledge to an efficient use as 'the wisdom of crowds' under the banner of open science, then around the year 2030 we can increase the amount and the quality of innovation activities in technology and science, including research activities, even if the number of scholars in our country will decrease." (MEXT, 2015, first author's translation).
Despite its research policy to push science communication towards a two-way communication style (Kobayashi, 2019), it introduces "citizen science" within the globally expanding science and policy fields of open science and open innovation (Hecker et al. 2018). Contrary to Ui and Takagi, who were concerned with the question of how science can contribute to society and how science can address issues of citizens, MEXT targets an increased contribution of citizens to benefit formally institutional science. ${ }^{4}$ In the following section, we will explore contemporary realizations of citizen science, by juxtaposing citizen participatory science discourses and projects (top-down) with citizen radiation measuring labs (bottom-up).

\section{Science for, by, and with citizens = citizen science?}

Citizen science from top to bottom. What counts as citizen science in Japan and what does not? In the aforementioned White Paper (2015) on Science and Technology, MEXT equips us with two examples of "citizen participatory science" projects: the Hanamaru Maruhana project and the NicoNico Gakkai ("the smiling academic society"). Following the typology of Wiggins and Crowston (2011), the Hanamaru Maruhana project could count as a contributory form of citizen science, as it invites citizens to acquire the necessary data for professional scientists (Hanamaru Maruhana Project, 2019). Throughout the process, these scientists remain in charge of the design and analysis of the project. The same observation applies to the NicoNico Gakkai, although it hints at a co-creative strand of citizen science, as this society operates on a "user-generated contents" basis and aims to create a space where "users, business, and academia research collaborate to conduct research" (NicoNico Gakkai, 2019). More noteworthy for this study is that neither project adopts the term "citizen science" (in English), or shimin kagaku or shichizun saiensu (in Japanese). Do they consider themselves as citizen science projects? It seems it depends on the context of use: when researchers of Hanamaru Maruhana present their project in the English academic journal "Scientific Reports", they refer to their project as "citizen science"; when communicating to audiences in Japan, they refrain from using this term altogether (Suzuki-Ohno et al. 2017).

These cases are not unique. In his study of biodiversity monitoring (2016), Komatsu Naoya also uses the term shimin kagaku. For the purpose of his research, he provides a list of citizen science initiatives in the United States and in Japan. The list enclosed in his thesis consists of 31 Japanese projects, which are initiated by either nonprofit organizations, universities, or associations. They depend on citizens to collect data to research and/or monitor diversity in Japanese fauna and flora. When consulting the websites of each organization, one quickly comes to the conclusion that out of 31 organizations, none uses the term "citizen science" to identify themselves or explain their activities. Instead, the terms "citizen participatory project" (shimin sankaku (gata) purojekuto) reappeared 6 times. As "science" is left out of the equation and "participatory" is not exclusively used to describe scientific endeavors, these projects tend to fall in line with a broad range of participatory (sankaku) projects, such as town planning (machi-zukuri). Therefore, many projects that require citizens to engage with science, remain undetected as "citizen science" in Japan.

The previous examples touch upon a top-down understanding of citizen science, whereby formal institutions, such as universities, and organizations, including non-profit organizations (NPOs), initiate citizen engagement and citizens gather various kinds of data for them. Although the above findings only concern top-down citizen science, a look at the other side of the spectrum 
brings us to bottom-up citizen science, which is citizen-initiated or-driven (Haklay, 2013, Abe, 2015). These initiatives tend to take the form of bottom-up, community-driven practices that emanate from a specific public issue or concern (Irwin, 1995). To study these projects and to consider how citizen science is mobilized within these groups, we next consider citizen radiation measuring organizations (shimin hōshanō sokutei shitsu/jo/ sentā $),{ }^{5}$ as they represent a recent upsurge of bottom-up "citizen science" in Japan (Aldrich, 2013, Morita et al. 2013).

Citizen science from the bottom up. In an effort to cope with the aftermath of the 2011 Fukushima disaster, citizens across Japan started measuring radiation in the air, food, and soil. The largest active group, Minna no Data Site, counts more than 30 independent radiation measuring labs. Kimura (2016) has identified five types of citizen radiation measuring organizations, namely organizations started by antinuclear activists, farmers, evacuees, and parents, among others. Although our fieldwork has demonstrated this analysis to be valid, Kimura's analysis presents a too homogeneous picture, as our fieldwork rather draws attention to the diversity of these groups. Despite having in common the activity of measuring ionizing radiation, each group has a unique character, expressed in the location and physical space these organizations occupy, the activities they indulge in, and their interactions with local governments and professional scientists, thus presenting manifold manifestations of citizen science. The first author notes the sheer heterogeneity when describing each organization in her field dairy (March 2018):

"Diversity already becomes apparent the moment you arrive at their doorstep, as organizations are located in the city or in desolated areas; inside buildings, next to churches, in a former daycare center or on private property. This diversification is again manifested inside their office: while an organization in Iwaki has a lab and clinic at its disposal, another organization in Fukushima city, measuring only air pollution, is mainly managed from behind a desk. Safecast, an international organization based in Tokyo driven by a core group of mostly foreigners living in Japan, only occupies a corner office and is mostly run online. Two initiatives visited in Fukushima city and Sendai revolve around one core person, who runs the organization, while other groups, such as in Aizu Wakamatsu, can count on more than nine active members. Whether these members are payed employees or volunteers again varies from organization to organization. Heterogeneity continues in the way citizens (dis)connect with professional scientists or through their (non-)interaction with local governments: whereas an organization located in Iwaki employs at least one doctor and gained permission to measure on school sites, members at a lab in Minami Soma opt not to engage with professional scientists or with their local government."

The image that surfaces from this description accounts to the multiversity of citizen groups, pointing to the existence of dozens of small, local organizations. Despite the fact that networks among organizations, such as the Minna no Data Site, have been created, the landscape of citizen radiation monitoring labs remains highly fractured. During an informal conversation on the lack of an overarching citizen measuring organization, a citizen scientist active in Fukushima city explained that creating one big organization is not possible, considering that the array of small, local organizations enables citizens to respond to their concern or to what they feel the problem is, as not everyone perceives the same issue as the main problem (Informal conversation with first author, Fukushima city, November
2018). Finding a single term in Japanese or English that suitably captures these citizen-led activities thus remains difficult, as no such term exists (Abe, 2015).

Taking this observation into consideration the question arises "can we label these initiatives under the umbrella term citizen science"? This issue encompasses several obstacles, which fieldwork brought to our attention. First, as citizen radiation measuring groups in Japan are viewed as manifestations of civil society (Hasegawa, 2004), they are subjected to the same perception as citizen movements. This connotation is rather negative as the latter are often associated with anti-governmental, left-wing movements in Japan (see also Ibid, Chiavacci and Obinger, 2018). A founding member of the Tokyo-based international citizen science volunteer group Safecast, located in Tokyo, illustrates this point:

"The nuance of the word shimin [citizen] sort of comes from the activist side of society, I mean it actually should be a neutral word, shimin is citizen, it should be neutral instead. But the way it's been used and deployed literally it's been generally in terms of activism. We use it, we try to use it in the neutral sense. But it's funny because you know when I talk to people about Safecast in Japanese I have to say we are a shimin dantai [citizen group]. [...] A lot of people don't come into contact with shimin dantai on a day to day basis [..]. What's the alternative like I say we're a NPO [nonprofit organization], we're an environmental NPO, a shimin dantai. Those two terms have very different nuances. I think environmental NPO is somehow less weighted with the sense of oppositional activism." (Interview first author with member of Safecast, Tokyo, March 2018).

This observation does not only affect the image of citizen radiation measuring organizations. It also concerns the term "citizen science", considering its historical entanglement with antinuclear activism, particularly in the figure of the antinuclear chemist Takagi, thus making citizen science a politically charged concept (Nihon KS, 2015). Within the pool of our empirically studied citizen science organizations, only Safecast explicitly employs the term shimin kagaku and citizen science (Safecast, 2019). Yet, this network has a strong global outlook and is rooted in hacker culture, contrary to other local citizen groups. The majority of local organizations, born out of the Fukushima nuclear accident, opt for other terminologies, such as "citizen radiation measuring place", "-lab", or "-center" (shimin hōshanō sokutei -jo, -shitsu, -sentā). Their "apolitical” (Kimura, 2016) attitude is also suggested in their efforts to disconnect their activities from antinuclear activism, as the following excerpt from an interview with a member of an organization in Nagoya indicates:

"What's a little tricky is the promise [made within a network of organizations] not to mention that we are against the government or that we are fighting against the government. We agreed that if we just measure accurately, the truth will shine through. If we start saying that we are against [the government], people will label us as against [the government]. So it becomes more difficult for everyone to join us. [...] So we try not to do this, and place how to measure accurately in the first place, but we, as an individual organization, are a bit different, because when there is a protest, we will all go. In this way the circumstances of each measuring organization are different." (Interview first author with member of a citizen science organization, Nagoya, November 2018, first author's translation). 
Considering that citizen activism evokes a negative image, and that some of the earliest citizen groups measuring radiation, including the Citizen Nuclear Information Center (Tokyo), have strong ties to antinuclear activism, "antinuclear" is a label many organizations initiated in the wake of Fukushima try to avoid. Disasters such as the Fukushima nuclear accident trigger different publics into action (Hasegawa, 2004, Leblanc, 1999). These citizens are not solely-or even necessarily-antinuclear activists, but primarily concerned citizens, whose main driver is to protect (in Japanese "mamoru") and serve their community, as conventional information sources failed to do so (Morita et al. 2013). By publicly distancing themselves from activism, these organizations may gain credibility within their community. Born out of a sense of necessity (Morita et al. 2013, Kimura, 2016), these groups should therefore not be labeled as activists as such, but rather as active by default.

Even if personal convictions lean towards antinuclear feelings, the organizations as such avoid taking a polarizing position, rather focusing on gathering the "right" data:

"We measure data that aren't lies, and we properly make our data public. Let aside whether it is good or bad. It is not up to us to say this. The one who should judge is the individual." (Interview first author with member of a citizen science organization, Nasu, March 2018, first author's translation).

Albeit subjected to the same standards of general scientific enquiry (Morris-Suzuki, 2014, Coletti et al. 2017, Brown et al. 2016, Kuchinskaya, 2019), the scientific facts and evidence produced by these citizen groups serve the needs of the community, allowing them to gain control over their lives:

"[...] Citizen science connects directly to our lives: is the dose of my meal okay, is the school where my child goes to contaminated? I think it readily produces information that I can use in my life. How can I put it... Saying that for this percentage out of so many thousands of people, it is like this, I know that that must be serious or that it is valuable data, but what I want to know is not that, what I want to know is how can I really know, how can I get the data that informs me about my child, my family, my body". (Interview first author with a member of a citizen science organization, Iwaki, March 2018, first author's translation).

Rather than making a contribution to scientific research, these citizen organizations require actionable data (Morita et al. 2013, Morris-Suzuki, 2014) by exploiting technology and science to understand the impact of technology gone awry, as illustrated by this tagline of a Tokyo-based radiation monitoring group: “To measure, to know, to live" (Hakaru, shiru, kurasu; Brochure published by citizen radiation measuring lab based in Tokyo).

The data being collected, then, are issue-driven (Marres, 2005) and serve a public goal, namely that of the community the organization identifies with:

"we conduct measurements/verify radiation in the close living environment of children, taking into account 'timeliness' and necessary 'amusement' essential to thWelcomee healthy growth of children" (website organization based in Fukushima city, first author's translation).

Thus, the approach and the purpose of science (and technology) is rooted in its functionality towards the community, implying that science is not the purpose of organizations, but rather a tool (Marres, 2005). As "the community" is the common denominator, organizations display flexibility in the range of activities they engage in, expanding their scope of activities and services to go beyond measuring radiation, thereby incorporating different forms of expertise, such as medical healthcare. A demand for medical care from the local population urged the local citizen radiation-measuring organization in Iwaki to set up a medical clinic in 2017. Today, it employs at least one doctor. Besides the organization in Iwaki, the group in Aizu Wakamatsu provides medical and psychological support to the public, for which they solicit two medical doctors, who work on a voluntary basis. More than 7 years after the nuclear accident, this initiative remains necessary to the local community: while conducting fieldwork at the organization in Aizu Wakamatsu more than five local residents, mostly mothers with their children, came to consult a doctor. Next to medical health care, the organization in Aizu Wakamatsu organizes "Let's talk meetings" to discuss a broad range of issues and concerns related to radiation contamination, creating a venue for citizens to learn about radiation and to address mental strains.

The above examples portray how citizen radiation measuring organizations relate to the concept of citizen science and testify to the heterogeneity of realizations of citizen science in Japan. By discussing these examples, it becomes clear that grassroots citizen radiation measuring groups in Japan enact a particular form of science, geared towards the needs of the local community with which citizens can identify. It also demonstrates flexibility in what it means to be a "citizen radiation measuring lab", incorporating activities demanding different forms of expertise beyond scientific renditions of "measuring radiation". This extension of expertise and the question of what counts as science, fact, and evidence are well-established topics within science and technology studies, pertaining to the question how various publics perceive scientific knowledge and the value of lay knowledge (Wynne, 1998), as well as practices of co-production (Jasanoff, 2004) ${ }^{6}$.

In the next section, we consider how such extensions challenge and potentially complement, formal institutional top-down approaches to radiation measurement and monitoring both in Japan and abroad. Drawing on the notions of "co-creative innovation" and "social space" (Rip and Joly, 2012) we consider the contributions social scientists can make in this area-both as researchers of citizen science and as potential facilitators of a "citizen social science" (Perello et al. 2020).

\section{Discussion: opening new spaces for expertise}

Our fieldwork indicates that despite high levels of public distrust in scientists, citizens in Japan occasionally seek out scientists to engage directly with society: by having scientists perform crosschecks to assure the accuracy of citizens' measurements; by obtaining experts' advice on measuring methods; and by inviting them to lecture at study meetings for members of citizen radiation measurement groups or the general public (interview first author with members citizen organizations, Aizu Wakamatsu, Iwaki, Shinjuku, Fukushima city 2018). Although collaboration with professional scientists is generally limited to consultation on an individual, informal basis, in some cases experts constitute an integral part of the group, like in Nagoya, or have acted as central figures in the creation of a citizen radiation measuring lab, such as in Nasu. There, a university professor was closely involved in the setup of the local citizen science group, but has also been an important catalyst for members to pick up a Geiger counter and start monitoring themselves (focus group first author with citizen scientists, Nasu, 2018).

As citizens and professional scientists search and construct opportunities for interaction, they demonstrate the potential of "co-creative innovation" (Cabinet Office, 2015). Although the notion of co-creative innovation as presented in policy documents of the Japanese government, suggests a modest role for citizens in scientific data collection, some Japanese researchers 
have stretched its potential by providing an alternative discourse -one that presents innovation as creating spaces with all the relevant actors beyond conventional expert-led citizen science (Hayashi, 2018). This creation of social spaces not only serves community science but also facilitates co-creative innovation across multiple communities, networks, sectors, and regions. From this perspective, "grassroots" does not necessarily imply a disconnection between citizens on the one hand and scientific experts or public authorities on the other (Ornetzeder and Rohracher, 2013). In Koganei and Iwaki city, various stakeholders, including local governments and citizens, have collaborated in unprecedented ways to jointly tackle nuclear risk governance challenges, including large-scale, long-lasting environmental contamination, disagreement between experts on how to act, asymmetrically perceived risks and benefits, and stigmatization of populations in affected areas (NAIIC, 2012, IAEA, 2014, Yoshizawa, 2012). These processes and the social spaces in which they emerge, can open onto more fruitful, equal, localized exchanges between scientific experts, regulatory bodies, and publics (Rip and Joly, 2012).

Social science has a unique role to play in expediting exchanges and connection between the formal and the informal, and assisting in the design of co-created social spaces, as for example Suzuki (2017) demonstrates by arranging an information platform and setting up regional round tables to create meeting places for reconstruction and recovery. While conducting research and fieldwork in Japan and Europe between 2017 and 2019, we sought to initiate and facilitate direct exchanges between radiological protection experts, decision makers, citizen scientists, and local residents in citizen-driven radiation monitoring, with the explicit aim of exploring with these stakeholders how to integrate citizen science concepts and approaches into the governance of nuclear incidents/accidents in emergency preparedness, response, and post-disaster recovery (Van Oudheusden et al. 2019). In these processes and throughout our research, we have reflexively considered what social science research on, with, or for citizen science is-and should be-about (Van Oudheusden et al. 2020). Here, a criticism voiced by local Fukushima residents against social scientists springs to mind: "[W]hat you call research does not give benefits to local people" (Miyamoto and Ankei, 2008, cited in Ankei, 2013, p.24). This strong condemnation should give us pause to think and consider how a "citizen social science" (Perello et al. 2020) can involve citizens into social scientific research. Simultaneously it requires a heightened sensitivity towards "Social issues or concerns, self-expressed by groups of citizens" (Bonhoure et al. 2019).

Within this latter understanding of citizen social science, listening to the field becomes an important tool to accumulate not only concerns and issues expressed by citizens (Morris-Suzuki, 2014), but also to adopt and borrow terminologies used by citizens to generate a more "socially robust science" (Bonhoure et al. 2019, Nowotny, 2003). Robustness entails attending to the complexity of interactions between citizens, science, authorities, and their community. From our perspective, this includes paying careful and sustained attention to the language of citizen organizations and to the contexts these groups work in. Bearing in mind how terms and definitions shape citizen participation in science through localized expectations and understandings of "citizen" and "science". This study illustrated how Japanese citizen radiation measuring organizations only rarely employ the term "citizen science", instead opting for terms that disassociate their activities from activism. This finding suggests that if these terms are not contextualized, a situation arises where citizen science takes the form of an empty signifier; i.e., a concept or term that has become detached from its previous particular content and is easily misappropriated (Wullweber, 2008). Against this background, "citizen science" does not emerge as a concept of which the definition is shared among various stakeholders, nor as a term that all stakeholders feel comfortable identifying with. Thus, the risk of calling all grassroots movements "citizen science" is that this obscures various historical and cultural manifestations, as well as the historical and cultural background of Japanese or Asian forms of citizen science, how citizens themselves interpret their actions and activities, or do justice to the "many modes of citizen science" (Kasperowski and Kullenberg, 2019), which abound. Ideally, citizen science terms and concepts would be developed by, for and with citizens to better reflect the values, priorities, and stakes of its main agents and of all concerned parties.

\section{Conclusion}

By shedding light on designations of citizen science and their various (un)uses, we highlight in this study how Japanese understandings of citizen engagement in science differ from predominant Western understandings of citizen science (Haklay, 2013, Bonney et al. 2009, Eitzel et al. 2017). We use "citizen science" as a lens to open a space for careful consideration what citizen science means to different people in different contextseven within the same country or sociotechnical field. By examining the historical and social context of citizen science in Japan and by describing the heterogeneity of citizen responses after the Fukushima nuclear accident, we seek to emphasize the variety of citizen enactments and epistemic practices.

Our comparison suggests that prevalent understandings of citizen engagement in science do not easily translate across languages and cultures, particularly as citizenship in Japan emerges as a contested notion, specifically but not exclusively in the nuclear arena. This notion risks being subsumed under the generic expression of "citizen science", which is presently fashionable in the West but less so in Japan. Therefore, we stress the importance of attending to specificity, diversity and plurality, noting that there is not one citizen science at play but various enactments.

In pointing out diverse manifestations of citizen science, this study problematizes both overly cooperative conceptions of citizen science as a joint exploration that elicits only beneficial outcomes for science and society (e.g., an enhanced public understanding of science) and pessimistic accounts, which suggest that grassroots citizen science has no policy critical potential (Mirowski, 2017). It points towards its capacity to empower publics to create their own response to address needs and concerns, and develop novel forms of scientific citizenship.

Each of these considerations has implications for institutional reception and potential uptake, as they draw critical attention to what realizations of citizen science can perform or achieve and how they impact science and society. They bring into focus how citizens may envision and enact a form of citizen science distinct from formal, procedural enactments of citizen engagement with science, raising questions of in- and exclusion (in fact, formal institutions may well be excluded from citizen participation!), of the potential of co-creative innovation, the intention of scientific activities and the purpose of scientific data. For these reasons, formal institutions, expert communities, and citizens would do well to take these insights to heart, as terms, values, and norms shape the participation of stakeholders (local communities, public authorities, regulators, professional scientists) in science and technology.

Highlighting possible alternative narratives of science by, for, and with citizens requires an understanding of citizens' experiences in their own right and following their own trajectories. In order to tap into the heterogeneity of citizen science, garnering 
more insight into what citizen science means and how it is articulated and practiced by different stakeholders is urgent and important, as there are many problems that emerge when these questions are skirted over or remain unaddressed. Further research is needed to examine these challenges in ways that strengthen and develop the connections between citizen-driven approaches and institutional imperatives in the governance of radiation pollution and broader environmental issues.

\section{Data availability}

The dataset generated during and/or analyzed during the current study is not publicly available due to privacy restrictions, but is available from the corresponding author on reasonable request.

Received: 2 September 2019; Accepted: 9 March 2020;

Published online: 3 April 2020

\section{Notes}

1 In February-March 2018 (6 weeks) the first author conducted 13 semi-structured interviews with 10 organizations, of which 9 citizen science organizations actively measuring radiation. She revisited nine organizations in November-December 2018 (4 weeks). In the same period, she also interviewed members of six other organizations, of which five are involved in radiation measurement. Research participants from radiation measuring organizations were recruited via Japanese research contacts and through snowball sampling using these additional criteria: (a) main activity revolves around radiation measurement (food, air, and/or soil), (b) citizen-initiated and -driven organization, and (c) ongoing activities relate to citizen science.

2 The Kumamoto University School of Medicine was. e.g., instrumental in the determination of the Minamata disease, caused by mercury poisoning from a chemical factory (Sugiyama, 2015).

3 Being an English loanword, the pronunciation of shichizun saiensu comes closest to the English term "citizen science".

4 Contrary to the MEXT, the Ministry of Land, Infrastructure, Transport and Tourism, influenced by professional scientists such as Hiromi Kobori, shows more interest in a more bottom-up, collaborative type of citizen science (Ministry of Land, Infrastructure, Transport and Tourism, 2017).

5 In her research on citizen science after Fukushima, Kimura $(2016,2017)$ refers to these initiatives as Citizen Radiation Measuring Organizations (CRMOs). Although the term adopted in this article is identical to Kimura's research, we refer to the terminology used by citizen groups, namely shimin hōshanō sokutei shitsu, shimin hōshanō sokutei jo, or shimin hōshanō sokutei sentā, which translates as "citizen radiation measuring lab/place/center".

6 Nuclear experts in Japan and elsewhere have responded to the emergence of citizen labs and the rise of citizen-led measuring practices by drawing attention to questions of data accuracy, validity, reliability, etc. Various scientists in Tokyo and Fukushima are performing crosschecks of citizen-generated data. (Morris-Suzuki, 2014; Coletti et al. 2017; Brown 2018; Kuchinskaya, 2019)

\section{References}

Abe Y (2015) Measuring for what: networked citizen science movements after the Fukushima nuclear accident. Dissertation, University of Southern California

Aldrich DP (2013) Rethinking civil society - state relations in Japan after the Fukushima accident. Polity 45(2):249-264

Ankei Y (2013) The fieldwork ethics and positionality of tsuneichi miyamoto: A pioneer of border island studies in Japan. Eurasia Border Rev 4(1):19-42

Avenell S (2006) Regional egoism as the public good: residents' movements in Japan during the 1960s and the 1970s. Jpn Forum 18(1):89-113

Avenell S (2016) Antinuclear radicals: scientific experts and antinuclear activism in Japan. Sci Technol Soc 21(1):88-109

Beck U (1992) Risk society: towards a new modernity. SAGE Publications, London

Bonhoure I, Cigarini A, Vicens J, Perello J (2019) Citizen social science in practice: a critical analysis of a mental health community-based project. SocArXiv Papers. https://doi.org/10.31235/osf.io/63aj7

Bonney R, Ballard H, Jordan R, McCallie E, Phillips T, Shirk J, Wilderman C C (2009) Public participation in scientific research: defining the field and assessing its potential for informal science education. A CAISE Inquiry Group Report. Available via CIASE. https://www.informalscience.org/sites/default/ files/PublicParticipationinScientificResearch.pdf. Accessed 6 Mar 2020

Brown A (2018) Enhancing public information after radiation emergencies through citizen participation: seven years of lessons learned by the safecast project.
Paper presented at the international symposium on communicating nuclear and radiological emergencies to the public. IAEA, Vienna, 1-5 Oct 2018. http://streaming.iaea.org/20925. Accessed 30 Aug 2019

Brown A, Franken P, Bonner S, Dolezal N, Moross J (2016) Safecast: successful citizen-science for radiation measurement and communication after Fukushima. J Radiol Prot 36(2):82-101

Cabinet Office (2015) Fifth science and technology master plan 2017-2021 [In Japanese]. Available via Cabinet Office. https://www8.cao.go.jp/cstp/ kihonkeikaku/5honbun.pdf. Accessed 6 Mar 2020

Chiavacci D, Obinger J (eds) (2018) Social movements and political activism in contemporary Japan: re-emerging from invisibility. Routledge, New York

Citizen Science Initiative Japan (2018) About citizen science [in Japanese]. https:// www.shiminkagaku.org/whatcs/. Accessed 11 Dec 2019

Coletti M, Hultquist C, Kennedy WG, Cervone G (2017) Validating safecast data by comparisons to a U.S. Department of Energy Fukushima Prefecture aerial survey. J Environ Radioactivity 171:9-20

Eitzel MV, Cappadonna JL, Santos-Lang C, Duerr RE, Virapongse A, West SE, Kyba C, Bowser A, Cooper CB, Sforzi A, Metcalfe AN, Harris ES, Thiel M, Haklay M, Ponciano L, Roche J, Ceccaroni L, Shilling FM, Dörler D, Heigl F, Kiessling T, Davis BY, Jiang Q (2017) Citizen science terminology matters: exploring key terms. Citizen. Sci Theory Pract 2(1):1-20

Felt U (2018) Responsible research and innovation. In: Gibbon S, Prainsack B, Hilgartner S, Lamoreaux J (eds) Handbook of genomics, health and society. Routledge, Abingdon, p 108-116

Fujigaki Y (ed.) (2015) Lessons from Fukushima: Japanese case studies on science, technology and society. Springer, Switzerland

Gabrys J, Pritchard H, Barratt B (2016) Just good enough data: figuring data citizenships through air pollution sensing and data stories. Big data Soc 3 (2):1-14

Haklay M (2013) Citizen science and volunteered geographic information overview and typology of participation. In: Sui DZ, Elwood S, Goodchild MF (eds) Crowdsourcing geographic knowledge: volunteered geographic information (VGI) in theory and practice. Springer, Berlin, p 105-122

Hanamaru Maruhana Project. meme.biology.tohoku.ac.jp/bumblebee/. Accessed 11 Dec 2019

Hasegawa K (2004) Constructing civil society in Japan: voices of environmental movements. Trans Pacific Press, Burwood

Hasegawa K (2014) The Fukushima nuclear accident and Japan's civil society: context, reactions, and policy impacts. Int Sociol 29(4):283-301

Hayashi K (2018) The progress of open science and the development from citizen science to co-creative research [in Japanese]. Gakujutsu no Dōkō 23 (11):12-29

Hecker S, Haklay M, Bowser A, Makuch Z, Vogel J, Bonn A (eds) (2018) Citizen science innovation in open science society and policy. UCL Press, London

Hindmarch R (ed.) (2013) Nuclear disaster at Fukushima Daiichi: social, political and environmental issues. Routledge, New York

IAEA (2014) IAEA report on radiation protection after the Fukushima Daiichi accident: promoting confidence and understanding. Available via IAEA https://www.iaea.org/publications/11089/iaea-report-on-radiationprotection-after-the-fukushima-daiichi-accident-promoting-confidence-andunderstanding-0. Accessed 30 Aug 2019

Irwin A (1995) Citizen science: a study of people, expertise and sustainable development. Routledge, New York, NY

Jasanoff S (ed.) (2004) States of knowledge: the co-production of science and social order. Routledge, London and New York

Kaji M (2012) Role of experts and public participation in pollution control: the case of Itai-itai disease in Japan. Ethics Sci Environ politics 12(2):99-111

Kasperowski D, Kullenberg C (2019) The many Modes of Citizen Science. Science Technol Stud 2-7

Kimura AH (2016) Radiation brain moms and citizen scientists: the gender politics of food contamination after Fukushima. Duke Univ. Press, Durham

Kimura AH (2017) Citizen science in post-Fukushima Japan: the gendered scientization of radiation measurement. Sci Cult 28(3):1-24

Kimura AH, Kinchy A (2016) Citizen science: probing the virtues and contexts of participatory research. Engaging Sci Technol Soc 2:331-361

Kobayashi Y (2019) An outline of the history of science communication: its rapid expansion in Japan since 2000 [translated from Japanese]. Via Koyabashi Yoshihiko Blog. http://yoshikoba113blog.seesaa.net/article/463809818.html. Accessed 11 Dec 2019

Komatsu N (2016) Research concerning the improvement and evaluation of Japanese citizen science in preserving biodiversity [in Japanese]. Dissertation, Tokyo City University

Kuchinskaya O (2019) Citizen science and the politics of environmental data. Sci Technol Hum Values 44(5):871-880

Leblanc RM (1999) Bicycle citizens: the political world of the Japanese housewife. University of California Press, California

Lin W, Law J (2018) Where is East Asia in STS? East Asian Sci Technol Soc Int J 13 (1):115-136 
Marcus GE (1995) Ethnography in/of the world Ssystem: the emergence of multisited ethnography. Annu Rev Anthropol 24:95-117

Marres N (2005) Issues spark a public into being: a key but often forgotten point of the Lippmann-Dewey debate. In: Latour Bruno, Weibel Peter (eds) Making things public. MIT Press, Massachusetts, p 208-217

Ministry of Education, Culture, Sports, Science and Technology (MEXT) (2015) White paper on science and technology [in Japanese]. Available via WARP. http://warp.ndl.go.jp/info:ndljp/pid/11293659/www.mext.go.jp/b_menu/ hakusho/html/hpaa201501/detail/1358751.htm. Accessed 6 Mar 2020

Ministry of Land, Infrastructure, Transport and Tourism (2017) Guidebook for "citizen science" on sewerage [In Japanese]. Available via MLIT. http://www. mlit.go.jp/common/001178471.pdf. Accessed 6 Mar 2020

Ministry of the Environment (2013) Guideline concerning measurements methods of the concentration of radioactivity [in Japanese]. Chapter 5. Available via MOE. https://www.env.go.jp/jishin/rmp/attach/haikibutsug105_ver2.pdf. Accessed 6 Mar 2020

Mirowski P (2017) Against citizen science. Available via AEON. https://aeon.co/ essays/is-grassroots-citizen-science-a-front-for-big-business. Accessed 30 Aug 2019

Miyamoto T, Ankei Y (2008) Annoyance as being investigated: a book to read before going to the field [in Japanese]. Mizunowa Shuppan, Tokyo

Morita A, Blok A, Kimura S (2013) Environmental infrastructures of emergency: the formation of a civic radiation monitoring map during the Fukushima disaster. In: Hindmarsh R (ed.) Nuclear disaster at Fukushima Daiichi: social, political and environmental issues. Routledge, New York, NY, p 78-96

Morris-Suzuki T (2014) Touching the grass: science, uncertainty and everyday life from Chernobyl to Fukushima. Sci, Technol Soc 19(3):331-362

Mother's Radiation Lab Fukushima (2019) About us. https://tarachineiwaki.org/ english. Accessed 30 Aug 2019

National Diet of Japan (2012) The official report of the Fukushima nuclear accident independent investigation commission (NAIIC) (executive summary). Available via National Diet of Japan. http://www.nirs.org/fukushima/ naiic_report.pdf. Accessed 6 Mar 2020

NicoNico Gakkai. About NicoNico Gakkai [in Japanese]. http://niconicogakkai.jp/ info/about. Accessed 11 Dec 2019

Nihon KS (2015) Citizen science - getting to know the world through the wisdom of the crowds [in Japanese]. Available via Nikkei. https://www.nikkei.com/ article/DGKKZO90805970R20C15A8MY1000/. Accessed 30 Aug 2019

Nowotny H (2003) Democratising expertise and socially robust knowledge. Sci Public Policy 30(3):151-156

Ornetzeder M, Rohracher H (2013) Of solar collectors, wind power, and car sharing: comparing and understanding successful cases of grassroots innovations. Glob Environ Change 23(5):856-867

Perello J, Mayer K, Franzen M, Arza V, Albert A (eds) (2020) Citizen social science: active citizenship versus data commodification. Palgrave Communications (in press)

Rip A, Joly PB (2012) Emerging spaces and governance A position paper for EUSPRI. Tech Rep

Safecast (2019) About safecast. https://blog.safecast.org/about/. Accessed 30 Aug 2019

Shirk JL, Ballard HL, Wilderman CC, Philips T, Wiggins A, Jordan A, McCallie E, Minarchek M, Lewenstein BV, Krasny ME, Bonney R (2012) Public participation in scientific research: a framework for deliberate design. Ecol Soc 17 (2):29-48

Strasser BJ, Baudry J, Marh D, Sanchez G, Tancoigne E (2018) "Citizen science"? Rethinking science and public participation. Sci Technol Studies 32(2): $52-76$

Sugiyama S (2015) 6. Minamata disease: interaction between government, Scientists, and media. In: Fujigaki Y (ed.) Lessons from Fukushima: Japanese case studies on science, technology and society. Springer, Switzerland, p 125-140

Suzuki H (2017) Aiming for broad-scale consensus for sustainable regional revitalization and towards regenerating livelihood - Sustainable recovery goals for Fukushima. https://goo.gl/NeP62p. Accessed 6 Mar 2020

Suzuki-Ohno Y, Yokoyama J, Nakashizuka T, Kawata M (2017) Utilization of photographs taken by citizens for estimating bumblebee distributions. Sci Rep. 7(1):1-11

Takagi J (1999a) Living as a citizen scientist [in Japanese]. Iwanami Shoten, Tokyo

Takagi J (1999b) Aiming for a science of citizens [in Japanese]. Asahi Shinbunsha, Osaka
Tsukuhara T (2019) Informal histories of STS in East Asia: legacies and networking: Japanese STS in transformation. East Asian Sci Technol Soc Int J 13 (1):143-149

Ueda A (2006) The type of 'citizen scientist' society needs now [in Japanese]. In: The Japan society for studies of voluntary activities (ed.). Special issue: cocreated culture, community symbiosis. Sun Art Publishing, Osaka, p 68-73

Van Oudheusden M, Kenens J, Yoshizawa G, Mizushima N (2019) Workshop report: learning from citizen science after Fukushima - probing the role and potential of citizen science in nuclear science and technology governance in Japan and Belgium. Available via ORBI. https://orbi.uliege.be/handle/2268/ 235561. Accessed 6 Mar 2020

Van Oudheusden M, Kenens J, Yoshizawa G, Mizushima N, Van Hoyweghen I (2020) Developing pathways for nuclear science, technology and innovation governance: Reflections on a Japanese-Belgian research project on citizen science after Fukushima [in Japanese]. J Sci Technol Stud 18:58-72

Wiggins A, Crowston K (2011) From conservation to crowdsourcing: a typology of citizen science. HICSS '11 Proceedings of the 2011 44th Hawaii International Conference on System Sciences. 1-10

Wullweber J (2008) Nanotechnology an empty signifier à venir? A delineation of a techno-socio-economical. Sci Technol Innov Stud 4(1):27-48

Wynne B (1998) Chapter 2: May the sheep safely graze? A reflexive view of the expert-lay knowledge divide. In: Lash S, Szerszynski B, Wynne B (eds) Risk, environment and modernity: towards a new ecology. Sage, London, $\mathrm{p} 44-83$

Yoshizawa G (2012) Anticipatory and participatory governance: revisiting technology assessment on nuclear energy in Japan. J Disaster Res 7:1-6

\section{Acknowledgements}

The research team thank all research participants for their time and contributions. They also thank Catrinel Turcanu (SCK CEN) and Ueda Akifumi (CSIJ) for their input. Research for this project received support through a Bilateral Joint Research Agreement between the Research Fund - Flanders (FWO) and the Japanese Society for the Promotion of Science (JSPS) (VS05517N). Fieldwork reported in this study was realized in the framework of a PhD at SCK CEN and KU Leuven. The second author's work is funded by the European Commission's Horizon 2020 MSCA-IF-2018 research funding scheme (grant number 836989). Go Yoshizawa received funding from the European Union's Horizon 2020 research and innovation programme under the Marie Sklodowska-Curie grant agreement No 796520.

\section{Competing interests}

The authors declare no competing interests.

\section{Additional information}

Correspondence and requests for materials should be addressed to J.K., M.V.O., G.Y. or I.V.H.

Reprints and permission information is available at http://www.nature.com/reprints

Publisher's note Springer Nature remains neutral with regard to jurisdictional claims in published maps and institutional affiliations.

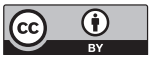

Open Access This article is licensed under a Creative Commons Attribution 4.0 International License, which permits use, sharing, adaptation, distribution and reproduction in any medium or format, as long as you give appropriate credit to the original author(s) and the source, provide a link to the Creative Commons license, and indicate if changes were made. The images or other third party material in this article are included in the article's Creative Commons license, unless indicated otherwise in a credit line to the material. If material is not included in the article's Creative Commons license and your intended use is not permitted by statutory regulation or exceeds the permitted use, you will need to obtain permission directly from the copyright holder. To view a copy of this license, visit http://creativecommons.org/ licenses/by/4.0/.

(C) The Author(s) 2020, corrected publication 2022 